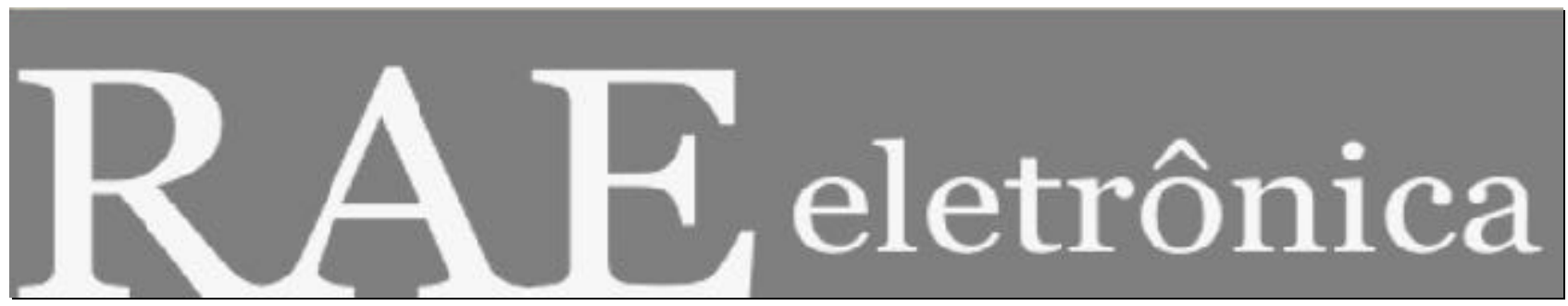

\title{
PARADOXOS ORGANIZACIONAIS, GESTÃO DE PESSOAS E TECNOLOGIA NA SOUZA CRUZ
}

Por:

\section{Isabella Vasconcelos}

\section{André Ofenhejm Mascarenhas}

Flávio Carvalho de Vasconcelos

RAE-eletrônica, v. 3, n. 2, Art. 25, jul./dez. 2004

http://www.rae.com.br/eletronica/index.cfm?FuseAction=Artigo \&ID=1994\&Secao=GESTREL\&Volu $\mathrm{me}=3 \&$ Numero $=2 \& \mathrm{Ano}=2004$

CCopyright, 2004, RAE-eletrônica. Todos os direitos, inclusive de tradução, são reservados. É permitido citar parte de artigos sem autorização prévia desde que seja identificada a fonte. A reprodução total de artigos é proibida. Os artigos só devem ser usados para uso pessoal e nãocomercial. Em caso de dúvidas, consulte a redação: redacao@ rae.com.br.

A RAE-eletrônica é a revista on-line da FGV-EAESP, totalmente aberta e criada com o objetivo de agilizar a veiculação de trabalhos inéditos. Lançada em janeiro de 2002, com perfil acadêmico, é dedicada a professores, pesquisadores e estudantes. Para mais informações consulte o site www.rae.com.br/eletronica.

\section{RAE-eletrônica}

ISSN 1676-5648

(C2004 Fundação Getulio Vargas - Escola de Administração de Empresas de São Paulo.

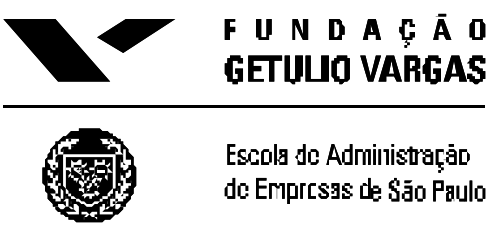




\title{
PARADOXOS ORGANIZACIONAIS, GESTÃO DE PESSOAS E TECNOLOGIA NA SOUZA CRUZ ${ }^{\mathrm{i}}$
}

\section{RESUMO}

Pesquisas sobre o atual contexto da gestão de pessoas no Brasil indicam uma importante fase de transição pela qual a área de RH passa atualmente, de uma atuação predominantemente operacional para modelos mais orgânicos de gestão de pessoas. Os autores pesquisados mostram que a aprendizagem organizacional é uma variável progressivamente defendida e valorizada pelos profissionais da área nos novos modelos de gestão que emergem no Brasil. Esta época de transição de modelos tem como característica a intensificação de paradoxos e contradições nas organizações, que adotam rapidamente o novo discurso, mas encontram dificuldades operacionais para implementação das novas estruturas e comportamentos próprios aos novos modelos. Mostrados por meio de um estudo de caso como a organização estudada conseguiu evitar os efeitos do paradoxo discurso $\mathrm{x}$ prática gerencial por meio da emergência do modelo político de gestão de pessoas. $\mathrm{Na}$ medida em que mudanças graduais permitiram a construção de novas competências e novos relacionamentos necessários à implementação de sistemas de informação, consolidourse um novo sistema organizacional, mais propício à aprendizagem.

\begin{abstract}
Research on the context of human resource management in Brazil indicates an important transition phase which HR departments face nowadays, from operational models of management to more strategic ones. Several authors show that organizational learning has an increasingly important role in the new human resource management models that emerge in Brazil. In this transition, paradoxes and contradictions usually appear in organizations, that quickly adopt new discources but face difficulties in implementting the appropriate new organizational structures and behaviours. Through a case study, we show how an organization managed to avoid the undesirable effects of discource $x$ practice paradox through the consolidation of a political model of human resource management. As these gradual changes allowed the social actores to build new competencies e relationships necessary to the implementation of the information systems in HR processes, organization is nowadays an adequate environment for learning.
\end{abstract}

\section{PALAVRAS-CHAVE}

Gestão de pessoas, paradoxos organizacionais, aprendizagem, mudança organizacional.

\section{KEY-WORDS}

Human resource management, organizational paradoxes, organizational learning, organizational change. 


\section{INTRODUÇÃO - A TRANSIÇÃO DE MODELOS DE GESTÃO DE PESSOAS NO BRASIL E A TECNOLOGIA DA INFORMAÇÃO}

Pesquisas sobre o contexto da gestão de pessoas no Brasil e exterior indicam uma importante fase de transição pela qual a área de RH passa atualmente, de uma atuação predominantemente operacional para modelos mais orgânicos de gestão de pessoas (Fischer, 1998; Fischer, 2002; Fischer e Albuquerque, 2001, Lacombe e Tonelli, 2000). Lacombe e Tonelli (2000), ao sugerirem um descompasso significativo entre a identificação de tendências pelos diversos formadores de opinião na área de RH e a prática efetiva de gestão de pessoas nas empresas brasileiras, indicam claramente esta fase de transição. O trabalho de Fischer e Albuquerque (2001), por meio de uma extensa pesquisa realizada na área de gestão de pessoas no Brasil, confirma que os formadores de opinião em gestão de pessoas no Brasil adotam novos discursos que defendem a politização dos indivíduos nas organizações.

Neste contexto de transição, os autores mostram que a aprendizagem organizacional é uma variável progressivamente defendida e valorizada pelos profissionais nos novos modelos de gestão de pessoas que emergem no Brasil, chamados genericamente de "ARH como vantagem competitiva". Neste sentido, a implementação da tecnologia da informação vem sendo considerada uma maneira de se viabilizar novos arranjos organizacionais da área. A implementação crescente dos chamados sistemas de RH auto-atendimento é um indicativo desta tendência. Estes sistemas possibilitam o amplo acesso do funcionário a informações e funções personalizadas e relevantes à administração de seu relacionamento com a organização (Mascarenhas, 2003).

Neste artigo, abordamos a gestão de possíveis paradoxos organizacionais. Em uma época de transição de modelos, há a intensificação de contradições nas organizações, que adotam rapidamente novos discursos, mas encontram dificuldades operacionais para implementar novas formas organizacionais e novos padrões de comportamento trata-se do paradoxo discurso $\mathrm{X}$ prática Este tipo de contradição é freqüente em situações nas quais se tenta consolidar novos modelos de gestão de pessoas sem no entanto atentar para a complexidade característica das organizações. Discutimos um estudo de caso de uma organização na qual foram criadas condições favoráveis para a consolidação de um novo modelo de gestão de pessoas baseado na aprendizagem.

Começamos o artigo explorando o paradoxo discurso X prática e seus efeitos nas organizações. Discutimos em seguida a implementação da tecnologia de informação e sua relação com certos contextos sociais. Apresentamos o modelo político de gestão de pessoas, condição para que a informação seja mais bem aproveitada para a aprendizagem de circuito duplo. Depois de apresentada a metodologia de pesquisa, analisamos o estudo de caso e concluímos o artigo discutindo desafios futuros à transição de modelos.

\section{OS EFEITOS DO PARADOXO DISCURSO x PRÁTICA}

O tema "paradoxos e organização burocrática" é clássico em teoria das organizações. Para Merton (1968), toda ação social produz um paradoxo básico tendo consequiências contraditórias, dado o fato de que para cada efeito desejado de uma ação, existe uma série de efeitos secundários, não desejados ou previstos, que se contrapõem aos efeitos buscados pelos indivíduos ao agir. Neste trabalho, utilizamos o conceito de paradoxo descrito por Lewis (2000). Este autor mostra como, a fim de atribuir sentido e compreender os sistemas complexos e ambíguos nos quais estão inseridos, os indivíduos têm a tendência a polarizar suas percepções em torno de elementos contraditórios e opostos (Lewis, 2000). A partir disso, eles começam a agir em função desta percepção polarizada. Paradoxos são assim 
realidades socialmente construídas, a partir de percepções simplificadas dos atores sociais, que, ao tentarem atribuir sentido à sua experiência, representam os sistemas complexos nos quais estão inseridos em torno de duas percepções contraditórias que passam a orientar a sua ação (Vasconcelos, Motta e Pinochet, 2003).

Abordamos neste artigo a gestão do paradoxo discurso X prática, que pode ser conceituado como a existência simultânea de duas realidades contraditórias: o discurso da organização e a sua prática efetiva em relação a um mesmo objeto. $\mathrm{O}$ paradoxo discurso $\mathrm{X}$ prática gera percepções inconsistentes nos indivíduos, que polarizam a interpretação da realidade ao seu redor entre dimensões opostas "discurso" e "prática". São vários os efeitos indesejados do paradoxo discurso X prática nas organizações, conforme narrado nos artigos pesquisados (Lacombe e Tonelli, 2000). A partir de percepções contraditórias provocadas pelas organizações nas quais trabalham, polarizando sua percepção nas dimensões "discurso" e "prática" incoerentes, e de promessas e discursos gerenciais que produzem expectativas que não se realizam, alguns grupos de atores sociais desenvolvem reações defensivas que aumentam o nível de frustração, tensão e estresse no sistema organizacional. Estas tensões nas organizações conduzem a fenômenos como a resistência organizacional e a emergência de conflitos, que impedem a consolidação de processos de mudança e reestruturação (Kets de Vries, 1995).

A piora do clima orga nizacional deve-se às frustrações geradas por estas contradições, como narram diversos estudos. Mais especificamente, quando "compram" os ideais de qualificação e aprendizagem pregados pelo discurso oficial, vários indivíduos sentem que este objetivo está em contradição com o trabalho mecânico que executam, que os impede de alcançarem concretamente estes objetivos, construindo novas competências. Esta insatisfação no ambiente de trabalho bem como um estilo gerencial incompatível com a aprendizagem organizacional explica o fato da implementação de sistemas de informação baseados nestas competências falhar ou do sistema ser implementado, mas não ser utilizado na prática como deveria (Vasconcelos e Vasconcelos, 2002; Carvalho e Lopes, 2001; Vieira e Misoczky, 2001; Leão Jr., 2001). Desta forma, reforça-se o ciclo vicioso: contradições muito grandes entre o discurso e a prática gerencial, produzindo nos indivíduos expectativas de desenvolvimento que não são concretizadas na prática, dificultam construção das competências necessárias à implementação com sucesso de certos sistemas de informação que exigem maior autonomia e preparação técnica dos indivíduos, reforçando ainda mais a distância discurso-prática na mesma organização (Teixeira, Hastenreiter e Souza, 2001; Seleme e Andrade, 1991; Souza, 2000; Soares e Pimenta, 2000).

\section{IMPLANTAÇÃO DE TECNOLOGIAS DA INFORMAÇÃO E MODELOS DE GESTÃO DE PESSOAS}

Shoshana Zuboff descreve o fato de que, por sua própria natureza, a tecnologia da informação atual é caracterizada por uma dualidade fundamental. Em primeiro lugar, a tecnologia pode ser utilizada para automatizar operações. O objetivo é substituir o esforço e a qualificação humanos pelo trabalho de máquinas, que permite que os mesmos processos sejam executados a um custo menor, com mais controle e continuidade. Esta função está relacionada ao modelo industrial e permite que se melhorem continuamente os processos e que se atinja maior eficiência nos procedimentos já conhecidos e sistematizados (Zuboff, 1994 e 1988). 
A tecnologia tem, entretanto, um outro potencial: a informatização. Neste caso, vai-se além da mera automação, gera-se e divulga-se uma informação nova que pode aperfeiçoar o próprio sistema. Esta função da tecnologia está vinculada ao modelo informacional e permite a comparação de diferentes sistemas e a geração de informação nova, útil para o indivíduo que trabalha na interface com a máquina. Ao aumentar o conhecimento sobre a natureza do próprio trabalho, a tecnologia informatizante permite o questionamento de seus métodos e a sua reconfiguração, se necessário.

Como coloca Zuboff (1994), estas duas funções da tecnologia podem levar a organização a caminhos divergentes. Uma estratégia que enfatiza a automação concentra-se na máquina inteligente, em volta da qual os indivíduos trabalham de forma mecanizada. A estratégia informatizante, ao contrário, reconhece o valor e a função da máquina inteligente, mas somente no contexto de sua interdependência com pessoas inteligentes e motivadas à aprendizagem e a inovação. $\mathrm{O}$ modelo de gestão de pessoas apresentado a seguir vai ao encontro da estratégia informatizante.

\section{GESTÃO DE PESSOAS NAS EMPRESAS BRASILEIRAS E O MODELO POLÍTICO DE GESTÃO DE PESSOAS}

Os padrões de relacionamento entre empresas e empregados, mediados e administrados pela área de RH, sofreram significativa evolução no decorrer do último século. A literatura geralmente trata deste desenvolvimento a partir do conceito de modelo de gestão de pessoas. Segundo Fischer (2002), o modelo de gestão de pessoas é a maneira como uma organização se organiza para gerenciar e orientar o comportamento humano no ambiente de trabalho.

Diversas pesquisas exploram o perfil da gestão de pessoas no Brasil. Lacombe e Tonelli (2000) mostram que a abordagem estratégica de $\mathrm{RH}$ ainda não é uma realidade totalmente implementada nas empresas brasileiras. A pesquisa empreendida pelas autoras destaca a existência de três grupos de empresa: o primeiro, com $28 \%$ da amostra é composto por empresas cujas áreas de RH tinham preocupações estritamente operacionais; o segundo, com 19\% da amostra é composto por empresas cuja gestão de pessoas estava estruturada em torno de questões estratégicas (como o papel de RH na empresa, o foco do negócio, a mudança constante e as metas de longo prazo); o terceiro grupo, com 53\% das empresas, parece estar em uma fase de transição entre os dois estágios. A partir deste cenário, podemos ainda sustentar que a menor parcela das organizações, o segundo grupo, estrutura a gestão de pessoas a partir dos princípios do modelo político, descrito por Brabet (1993). Descreveremos brevemente este modelo a seguir.

O modelo político de gestão de pessoas está associado às organizações pós-industriais, ou orgânicas, e diferencia-se do modelo instrumental de gestão de pessoas, associado às organizações industriais ou mecânicas. Este modelo favorece a emancipação dos indivíduos, o seu desenvolvimento político e cognitivo e o seu acesso a uma identidade autônoma na organização. Neste modelo de gestão, reconhece-se a existência de conflitos na organização, mas busca-se superá-los através da negociação, chegando-se a propostas de consenso entre as partes.

O modelo político visa oferecer possibilidades de debate e negociação na organização, a fim de promover o contraditório em busca de soluções mais completas em torno das quais se obtenham os consensos. Busca-se vislumbrar as diversas opções de ação antes de decidir, tendo-se como pressuposto que esta é uma forma mais inteligente de se lidar com a realidade complexa. O planejamento por cenários é um dos procedimentos adotados neste sistema. Um bom gerente, segundo este modelo, é um árbitro que tem como objetivo obter esta coesão integrando os interesses particulares dos diferentes 
grupos de atores sociais visando à obtenção de uma solução negociada junto à direção da empresa, resultando em uma espécie de "pacto político" (Brabet, 1993; Mascarenhas, 2003; Vasconcelos e Vasconcelos, 2002). As principais características do modelo político são:

- Eficiência econômica negociada, não correspondendo necessariamente à eficiência social em curto prazo (aceitação de conflitos, buscando-se no entanto absorvê-los através da negociação política);

- Empresa construída socialmente através da ação política dos diversos grupos organizacionais;

- Avaliação dos resultados feita pelos grupos organizacionais envolvidos no processo de decisão;

- Maior qualificação e politização dos grupos organizacionais para a interação social eficaz;

- Decisões racionais e éticas referindo-se à resolução de conflitos, à obtenção do consenso e às questões de poder.

- Indivíduos vistos como atores políticos válidos com potencial de desenvolvimento positivo buscando concretizar ativamente seus próprios interesses; modelo ético aplicado à organização.

O modelo político de gestão de pessoas está ligado ao conceito de construção de uma harmonia social no longo prazo, a despeito dos conflitos, e favorece a aprendizagem de circuito duplo, como veremos a seguir.

\section{A Aprendizagem organizacional e a inovação}

Chris Argyris (1992) dentro de uma linha cognitivista de análise, descreve a inovação e a aprendizagem organizacional. Argyris definiu o "single looping learning" e o "double looping learning", ou aprendizagem de circuito simples e aprendizagem de circuito duplo.

A aprendizagem de circuito simples baseia-se na detecção do erro e na sua correção, preservando-se, no entanto, os pressupostos do sistema operacional, ou seja, os valores de base que inspiram o funcionamento do sistema. Em se tratando de processos de produção ou administrativos, pode-se dizer que se trata da melhoria contínua de processos, na qual aprimora-se cada vez mais a eficiência de um dado processo, aperfeiçoando-se a sua prática e a sua execução até um nível ótimo, sem questionar-se, no entanto, os valores de base do sistema ou as suas etapas de funcionamento.

Já a aprendizagem de circuito duplo, base da inovação, envolve um processo de percepção e exploração das possibilidades do ambiente. Em primeiro lugar o indivíduo tem acesso a novas informações. Em segundo lugar compara as informações obtidas com as normas de funcionamento de um dado sistema ou processo, ao que se segue o questionamento da pertinência das normas de funcionamento do sistema e a iniciação de ações corretivas apropriadas, que podem envolver a mudança das práticas, valores e pressupostos do sistema ou processo antigo. No que se refere aos processos produtivos e gerenciais, propõe-se questionar habitualmente as bases de funcionamento do mesmo, a partir de novas 
informações obtidas, redesenhando-se o processo ou incluindo-se modificações relevantes no sistema desde que se façam necessário, reconfigurando-se o processo produtivo, a tecnologia ou a organização. No que se refere ao sistema cognitivo dos indivíduos, a aprendizagem de circuito duplo leva ao questionamento das próprias formas de comportamento e à mudança, logo ao perfil de um indivíduo autônomo e questionador, próprio do modelo político de gestão de pessoas.

Este tipo de aprendizagem, porém, não é simples e envolve contradições e paradoxos discurso x prática. Argyris e Schön (1978) em sua teoria perspectiva da ação (theory of action perspective) mostram que os indivíduos agem de acordo com suas crenças e pressupostos - valores que embasam sua ação e oferecem padrões (frames) de interpretação da realidade. Parte destes padrões, crenças e pressupostos podem ser modificados, mudando, pois, a ação e o comportamento dos indivíduos, pressuposto da aprendizagem. (Argyris e Schön, 1978). No entanto, Argyris e Schön descrevem as rotinas defensivas que impedem a adoção efetiva de práticas que se oponham às crenças básicas dos indivíduos. Os indivíduos não adotam comportamentos ou não tomam conhecimento de informações que lhes produza desconforto e angústia. Desta forma, existe uma defasagem entre a teoria adotada (o que se diz que se faz) e a teoria efetivamente praticada (como realmente se age): os indivíduos podem dizer que são favoráveis à incorporação de certo tipo de comportamento, eles podem até acreditar na validade dos mesmos, mas um bloqueio cognitivo os impede de adotarem estes comportamentos na prática. (Argyris e Schön, 1978).

Mostraremos a seguir como a implantação progressiva do modelo político de gestão de pessoas na organização favoreceu a consolidação de um perfil de funcionário autônomo e politizado na organização, mais apto à aprendizagem de circuito duplo.

\section{METODOLOGIA DE PESQUISA}

Esta pesquisa foi baseada no método do estudo de caso. O estudo de caso foi definido por Yin (2001, p. 32) como "um questionamento empírico que investiga um fenômeno contemporâneo com seus contextos de vida real, quando as fronteiras entre o fenômeno e contexto não são claramente evidentes, e nos quais múltiplas fontes de evidência são usadas".

Empreendeu-se um estudo de caso único em uma organização que passava por uma fase avançada no processo de implementação de um sistema de RH auto-atendimento. Estes sistemas possibilitam o acesso do funcionário a informações e funções personalizadas e relevantes à administração de seu relacionamento com a organização. Segundo Letart (1998), as cinco fases de implementação destes sistemas são:

1. Publicação de informações. A empresa disponibiliza comunicação de mão única para empregados sobre suas políticas e práticas de RH. Aplicações típicas desta fase são políticas e procedimentos, informações sobre benefícios, listas de funcionários quem é quem, diretório de serviços e notícias.

2. Pesquisas a banco de dados de RH. Aplicações desta fase também proporcionam comunicação de mão única para empregados. As aplicações, que têm requerimentos de segurança aumentados em relação à fase anterior, permitem que empregados tenham dúvidas respondidas a partir de questões específicas cujas respostas são buscadas em bancos de dados. Exemplos das possíveis funcionalidades nesta fase incluem coberturas correntes de benefícios, horários de trabalho, balanços de planos de aposentadoria e de pagamento de remuneração fixa e variável. 
3. Transações simples de RH. Aplicações incluem comunicação de mão dupla entre empregados e área de RH. É a fase inicial para a efetiva mudança na organização do trabalho da área de RH. Exemplo de funcionalidade de aplicações desta fase é a atualização de dados pessoais e dependentes.

4. Transações complexas de RH. Aplicações dessa fase diferenciam-se das anteriores pelo nível de complexidade da interação entre o usuário e a transação de RH sendo processada. Em adição à atualização de dados, estas aplicações envolvem a interação por meio de parâmetros do usuário, dados do perfil do usuário, cálculos e processamento interno de dados e transaçõ es de saídas múltiplas.

5. Processos eletrônicos de RH. A quinta fase da implementação de sistemas de RH auto-atendimento abrange a organização online de processos completos da área, ao invés de apenas transações isoladas. Assim, todas as fases necessárias para a realização de transações de RH estarão disponíveis, assegurando que todas as informações relevantes sejam disponibilizadas em ambos os sentidos.

Consideroutse que uma organização que passasse pelas fases quatro ou cinco era apropriada para nossa análise, pois poderíamos analisar a experiência em uma situação mais consolidada. Analisar um caso único foi a estratégia adotada por se tratar de um fenômeno recente no Brasil. A quase totalidade das empresas brasileiras com projetos em andamento ainda não passou da segunda fase de implantação dos sistemas RH auto-atendimento, não sendo, portanto, ideais para os fins desta análise (Mascarenhas, 2003).

Este estudo de caso é do tipo incorporado, isto é, a investigação foi dividida em algumas sub-unidades de análise ao invés de um estudo holístico que examinasse apenas a natureza global do fenômeno (Yin 2001). As unidades de análise incorporadas foram:

1. As percepções dos executivos da área de RH;

2. As percepções dos demais funcionários da área de RH; e

3. As percepções dos clientes da área de RH, isto é, os demais funcionários da empresa, em diversos níveis hierárquicos.

Em relação a cada unidade de análise, foram utilizados convenientemente os seguintes métodos de levantamento de dados: (1) entrevistas com pessoas relevantes; (2) análise de documentos; e (3) observação de processos. As 18 entrevistas foram semi-estruturadas, gravadas e duraram em médias 2 horas. Os documentos analisados incluíram comunicações internas, projetos, apresentações executivas e material de treinamento. Além disso, foram observados diversos processos de gestão de pessoas, informatizados e não-informatizados, no que diz respeito aos padrões de comportamento e interação entre os atores sociais.

Segundo Yin (2001), o modelo de estudo de caso deve ser passível de julgamento de sua qualidade, o que pode ser feito por algumas técnicas. A primeira refere-se à validade de construção do estudo. As técnicas para o aumento da qualidade são o uso de múltiplas fontes de evidência e o uso de informantes críticos para rever o relatório preliminar de estudo de caso. Neste estudo, foram analisadas evidências provenientes das três unidades de análise, permitindo que se pudesse compreender o fenômeno estudado sob diversos ângulos, além das diversas fontes de evidências a serem utilizadas, que se reforçam mutuamente evitando a utilização de informações tendenciosas ou equivocadas. Além destes fatores, o relatório preliminar de estudo de caso foi lido e discutido pelos informantes críticos identificados. Outras técnicas de julgamento da qualidade do estudo de caso relacionam-se a sua confiabilidade, que visam garantir que outro investigador obtenha os mesmos resultados caso se repita a mesma análise. A tática para garantir a confiabilidade neste estudo foi a utilização do protocolo de estudo de caso e a documentação do caso. 
Este estudo baseia-se na generalização analítica, que é a tentativa de se estender um conjunto particular de resultados a alguma teoria mais abrangente. Esse tipo de generalização difere-se da estatística por não se tratar de amostragem facilmente generalizável, isto é, o caso não é escolhido a partir da lógica da amostragem. Na generalização analítica, uma teoria previamente desenvolvida como modelo é utilizada para a comparação com os resultados empíricos do caso (Yin, 2001).

Após pesquisa preliminar sobre as iniciativas e estágios de implementação desses sistemas em organizações brasileiras, a Souza Cruz pareceu nos um caso adequado. A organização tem um amplo histórico de utilização da tecnologia da informação como ferramenta de competitividade em seus processos, e não como negócio central. Além de estar no quinto estágio de implementação da TI na área de RH, esta se mostrou prontamente disposta e preparada para dar o suporte necessário às atividades de pesquisa. Destacamos que a pesquisa foi realizada no mês de agosto de 2002, que o pesquisador não possui nenhum vínculo com a organização e que recebeu auxílio desta apenas para deslocamentos entre as unidades industriais estudadas.

\section{ESTUDO DE CASO: A EXPERIÊNCIA DE INFORMATIZAÇÃO DA GESTÃO DE PESSOAS NA SOUZA CRUZ S.A.}

A Souza Cruz, uma empresa do grupo British American Tobacco, é a décima quinta maior empresa privada no Brasil, com vendas de mais de 2,7 bilhões de dólares. Atuando nas áreas de fumo e cigarros, gera cerca de 4.700 empregos diretos, em postos de trabalho espalhados em todo o Brasil, além de 3.000 que trabalham para a empresa na época da safra de fumo. A empresa é uma das que mais recolhem impostos do país. São cerca de 45 mil famílias de produtores de fumo e cerca de 210 mil pontos de venda atendidos diretamente.

Atualmente, a Souza Cruz mantém diversas unidades espalhadas no Brasil, em uma estrutura organizacional marcada pela grande dispersão. A Central Administrativa, localiza da em São Paulo, reúne alguns departamentos administrativos. As unidades fabris de Uberlândia e Cachoeirinha concentram os funcionários da produção, enquanto que as quatro unidades de Processamento de Fumo, em Santa Cruz do Sul, Blumenau, Rio Negro e Patos reúnem os chamados "safreiros", funcionários da empresa em regime temporário, que trabalham na época da safra de fumo. A matriz, no Rio de Janeiro, concentra parte da administração e o corpo diretivo. Além disso, a empresa conta com estruturas de logística e vendas espalhadas por todo o Brasil, uma força de trabalho móvel e pulverizada responsável pela comercialização e entrega dos produtos em todo o território nacional.

\section{O histórico da gestão de pessoas e o projeto CSRH}

Devido às características relacionadas à organização e disposição geográfica da força de trabalho, a área de RH da empresa tem se defrontado, historicamente, com desafios peculiares no que se refere à gestão de pessoas. A área de RH, antes das mudanças relacionadas à implementação da tec nologia, era organizada de forma totalmente descentralizada. A partir da definição das políticas corporativas de gestão de pessoas, que era feita na matriz, cada unidade da empresa contava com uma estrutura própria e completa de RH que se ocupava de processos operacionais e parte dos processos estratégicos de administração de recursos humanos.

Os processos de $\mathrm{RH}$, tanto os operacionais como os estratégicos, eram realizados a partir da intensa interação entre os analistas da área e os gestores da organização e, por terem pouco apoio tecnológico, implicavam em grande quantidade de trabalho. Esses processos, antes da implementação da tecnologia, caracterizavamıse pela troca 
"Em 90 não existia informática no setor, não tínhamos sequer um micro, nós trabalhávamos com um terminal da IBM. Até 90, 91 era tudo manual. O que se fazia uma vez por mês era a rolagem da folha de pagamento, que era feita no Rio de Janeiro. A gente montava as informações aqui no IBM, não só a unidade de Uberlândia como as demais; essas informações iam para o Rio e eram emitidos os contra cheques. Nós não tínhamos acesso ao contra cheque e relatórios, como temos hoje, $99 \%$ era manual."

A estrutura organizacional e o desenho destes processos causavam uma morosidade ainda maior na administração de pessoas quando se tratava de funcionários baseados remotamente. Como colocou um executivo cliente de RH:

"Você imagina uma situação com a qual eu já convivi: eu emito um aviso de férias para alguém, e esta pessoa está sediada a quinhentos quilômetros de onde eu estou, e necessariamente ele tem que assinar este documento. Eu teria que alcançar essa pessoa e fazê-la assinar o documento e retorná-lo para mim, para então eu dar a minha assinatura e despachá-lo para uma central de recursos humanos, que iria colocar o input no sistema de férias de determinado funcionário."

Com o início da década de 90 a Souza Cruz começou a passar por um grande processo de racionalização organizacional, o que levou ao enxugamento da empresa. Durante esta década, a sua força de trabalho foi reduzida em 50\%, passando de 9.500 funcionários em 1991 para 4.700 em 2002. A área de RH, desta maneira, viu-se diante do desafio de adequar-se à nova realidade.

A pressão pela diminuição da força de trabalho da área levou à implementação de um amplo projeto que viabilizasse a total reorganização do RH. Este projeto deveria não somente possibilitar a redução do efetivo da área, acompanhando a racionalização da organização como um todo, mas principalmente, garantir novos padrões de atuação da área a partir da reorganização de seus processos e estruturas.

O projeto CSRH, Central de Serviços de Recursos Humanos, baseava-se na idéia da consultoria interna de recursos humanos. Segundo esta idéia, a área de RH deveria deixar de executar tarefas burocráticas e operacionais para concentrar-se na prestação de serviços estratégicos à organização. Neste sentido, os analistas de RH deveriam utilizar seus conhecimentos de questões humanas para concentrar-se no suporte às demandas das áreas clientes, de forma a melhorar a qualidade dos processos de gestão de pessoas na organização. Esta idéia parte do princípio que os processos de gestão de pessoas são de responsabilidade dos gerentes de linha, já que estes estão em contato direto e diário com as equipes.

\section{Os processos de gestão de pessoas antes e depois do projeto CSRH}

Os processos de administração de pessoas, antes do projeto CSRH, eram realizados pelos analistas de RH em cada unidade da organização. A maioria destes processos envolvia a interação intensiva entre estes analistas e os gestores, o que implicava em etapas desnecessárias de circulação de dados, em fluxos não-racionalizados nos quais o RH era o intermediário entre gestores e subordinados. Como colocou um cliente de $\mathrm{RH}$, o processo de reembolso de despesas é um dos maiores exemplos das dificuldades que a organização enfrentava neste sentido:

“[O reembolso de despesas] demorava vários dias. Imagina o seguinte: alguém em Angra dos Reis, ou em Cabo Frio, manda o papel pelo malote, que vai chegar em São Paulo para alguém assinar, digitar e depois creditar na conta do funcionário, isso vai demorar no mínimo cinco dias." 
O projeto CSRH promoveu a ampla informatização dos processos de administração de pessoas através de diversos sistemas interativos de RH auto-atendimento, como a URA (Unidade de Resposta Audível), e o SAF eletrônico (Serviço de Atendimento ao Funcionário). Atualmente, os membros da organização têm acesso a diversos sistemas que possibilitaram a descentralização da alimentação das informações relacionadas aos processos de RH. Estes sistemas possibilitaram a redução de etapas na execução destes processos, através da racionalização do fluxo de informações. O RH deixou de ser o intermediário nos processos de administração de pessoas. Como colocou um cliente da área de RH:

"A responsabilidade pelo input, que era da área de RH já que ela tinha que colocá-lo no sistema, foi pulverizado para as pessoas. Com isso, ganharam os funcionários e gerentes, dessa forma o funcionário faz o input e você como gerente faz só a aprovação, agora se você vai mudar o horário dele, vai transferir, vai promover, é uma tarefa do gerente."

Os sistemas de RH auto-atendimento da Souza Cruz são acessados através de terminais espalhados pelas unidades da empresa, no caso de funcionários da produção, dos terminais de microcomputadores dos funcionários de escritório e gestores, e de computadores portáteis da empresa, no caso de alguns gestores e funcionários alocados remotamente. Estes sistemas incluem diversas funções, como resumem os quadros abaixo. O SAF eletrônico é acessado por todos os funcionários da organização, por meio de senha individual, de forma indiscriminada:

\section{Tabela 1-SAF eletrônico: serviços acessados por todos os funcionários}

\begin{tabular}{|l|l|}
\hline Recrutamento interno & $\begin{array}{l}\text { O funcionário disponibiliza, de acordo com seus interesses, seu mini- } \\
\text { currículo pessoal, que é utilizado no processo de recrutamento interno. Tem } \\
\text { acesso às vagas disponíveis na organização, bem como inscrição no processo } \\
\text { de seleção. }\end{array}$ \\
\hline Contracheque & $\begin{array}{l}\text { O funcionário tem acesso ao contracheque do mês. O sistema permite a } \\
\text { impressão. }\end{array}$ \\
\hline Consulta de saldos & O funcionário tem acesso ao saldo de pagamentos diversos. \\
\hline Banco de Horas & $\begin{array}{l}\text { O funcionário tem acesso a informações sobre seu saldo de horas e controle } \\
\text { de horários. }\end{array}$ \\
\hline Auto-atendimento & $\begin{array}{l}\text { O funcionário tem acesso a ferramentas e informações como os últimos } \\
\text { contracheques, administração de férias e benefícios. O sistema permite a } \\
\text { impressão. }\end{array}$ \\
\hline Assistência à Saúde & $\begin{array}{l}\text { O funcionário tem acesso às políticas de assistência à saúde e ferramentas que } \\
\text { permitem administrar estes benefícios, como: solicitação de segunda via da } \\
\text { identificação, inclusão de dependentes, mudança de planos etc. }\end{array}$ \\
\hline
\end{tabular}

É disponibilizada ainda uma série de serviços aos gestores de equipes, destinados a gestão de pessoas sob sua responsabilidade. Estes serviços estão agrupados na página SAF Plus e Safreiros: 
Tabela 2-SAF Plus e Safreiros: serviços acessados pelos gestores.

\begin{tabular}{|c|c|}
\hline Admissão & $\begin{array}{l}\text { Os gestores têm acesso às ferramentas necessárias para a administração das } \\
\text { admissões. Solicitação de candidatos, aprovação, relatórios etc. }\end{array}$ \\
\hline Aprovação & $\begin{array}{l}\text { Os gestores aprovam diversas solicitações, como férias, alteração de horários, } \\
\text { registro de horários. }\end{array}$ \\
\hline Cadastro de funcionários & $\begin{array}{l}\text { Os gestores têm acesso a todas as informações pertinentes sobre os } \\
\text { funcionários. Dados cadastrais, dados funcionais, solicitação de transferência } \\
\text { e alteração de contrato de trabalho etc. }\end{array}$ \\
\hline Descontos & $\begin{array}{l}\text { Os gestores têm acesso às ferramentas necessárias para a administração de } \\
\text { descontos, como por exemplo telefonemas particulares, equipamentos } \\
\text { danificados e cargas incompletas. }\end{array}$ \\
\hline Administração de Férias & $\begin{array}{l}\text { Os gestores têm acesso às ferramentas necessárias para a administração das } \\
\text { férias. Solicitação, aprovação, demonstrativos etc. }\end{array}$ \\
\hline Histórico de operações & $\begin{array}{l}\text { Os gestores têm acesso ao histórico pessoal de operações nos sistemas em } \\
\text { duas opções: } 15 \text { e } 30 \text { dias. }\end{array}$ \\
\hline Tabelas & $\begin{array}{l}\text { Os gestores têm acesso a tabelas de cargos existentes na organização, horários } \\
\text { de trabalho, e datas limite para procedimentos de gestão de pessoas. }\end{array}$ \\
\hline Lista de funcionários & $\begin{array}{l}\text { Os gestores têm acesso a uma ferramenta de pesquisa para encontrar } \\
\text { funcionários da organização. }\end{array}$ \\
\hline Rescisão & $\begin{array}{l}\text { Os gestores têm acesso às ferramentas necessárias para a admin istração das } \\
\text { rescisões. Solicitação, simulação, exame demissional etc. }\end{array}$ \\
\hline Remuneração & $\begin{array}{l}\text { Os gestores têm acesso às ferramentas relacionadas à avaliação de } \\
\text { desempenhos dos funcionários de escritório, bem como aos históricos das } \\
\text { avaliações de desempenho, políticas de promoção, ferramentas de } \\
\text { administração de promoções. Este sistema alimenta também a remuneração } \\
\text { por mérito. }\end{array}$ \\
\hline Penas disciplinares & $\begin{array}{l}\mathrm{O} \text { gestor acessa ferramentas para a aplicação de penas disciplinares, como } \\
\text { advertências e suspensões. }\end{array}$ \\
\hline Hierarquia da empresa & O gestor tem informações sobre a estrutura organizacional. \\
\hline
\end{tabular}

Além do SAF eletrônico e do SAF Plus e Safreiros, o sistema de RH auto-atendimento traz diversas páginas por meio das quais os funcionários têm acesso a informações sobre a gestão de pessoas e as políticas da empresa, procedimentos de administração, sistema da avaliação de desempenho de executivos e administração de benefícios. Além desses serviços, a página da Universidade Souza Cruz concentra os cursos on line oferecidos aos 
funcionários:

\section{Ta bela 3 - Demais sistemas e ferramentas de gestão.}

\begin{tabular}{|c|c|}
\hline Universidade Souza Cruz & $\begin{array}{l}\text { Página por meio da qual são acessados cursos online de desenvolvimento } \\
\text { pessoal e profissional. Esses cursos são acessados por todos os funcionários } \\
\text { da empresa e são acompanhados por meio digital. A empresa disponibiliza } \\
\text { salas especiais em suas diversas unidades para o acompanhamento dos } \\
\text { cursos. }\end{array}$ \\
\hline Políticas de RH & $\begin{array}{l}\text { Os gestores têm acesso a todas as políticas de recursos humanos da empresa, } \\
\text { em um formato customizado. É possível encontrar as políticas sobre relações } \\
\text { industriais, recrutamento e seleção, idiomas, serviços de terceiros etc. }\end{array}$ \\
\hline Consultor de $\mathrm{RH}$ & $\begin{array}{l}\text { Os gestores têm acesso a explicações detalhadas sobre procedimentos } \\
\text { relacionados à gestão de pessoas, como desligamento, estagiários, penas } \\
\text { disciplinares, recrutamento e seleção, absenteísmo etc. }\end{array}$ \\
\hline RH Excellence & $\begin{array}{l}\text { Os gestores têm acesso a um grande número de relatórios customizados sobre } \\
\text { as características da força de trabalho da empresa. As informações incluem } \\
\text { perfil educacional, desempenho, movimentações, processos trabalhistas etc. }\end{array}$ \\
\hline $\begin{array}{lll}\text { MIDAS } & \text { Avaliação } & \text { de } \\
\text { desempenho }\end{array}$ & $\begin{array}{l}\text { Os gestores têm acesso aos formulários eletrônicos que devem ser } \\
\text { regularmente preenchidos, segundo os critérios da empresa, para se avaliar o } \\
\text { desempenho dos gestores subordinados. }\end{array}$ \\
\hline Sistemas especialistas de RH & $\begin{array}{l}\text { Os gestores têm acesso a outros sistemas de administração de pessoal, como } \\
\text { por exemplo o registro de horas extras trabalhadas. }\end{array}$ \\
\hline Reembolso Expresso & $\begin{array}{l}\text { Esta página traz as ferramentas de reembolso relacionadas aos benefícios da } \\
\text { empresa: assistência médica, oftalmológica, odontológica, medicamentos, } \\
\text { fundo emergencial, educação etc. Essas ferramentas possibilitam a } \\
\text { administração dos benefícios dos executivos. }\end{array}$ \\
\hline
\end{tabular}

A descentralização dos processos de administração de pessoas, viabilizada através da informatização, possibilitou a sua racionalização na medida em que etapas desnecessárias de seus fluxos de informações foram suprimidas. A antiga centralização dos dados por parte do RH, que era responsável pela sua introdução nos antigos sistemas, não existe mais. A descentralização da alimentação de dados possibilitou então maior rapidez e independência dos clientes de RH nestes processos. Um cliente de RH falou sobre a maior agilidade nos processos de administração de pessoas:

"Sobre esse processo, logicamente, hoje alguém imputa a solicitação de férias, como aconteceu comigo na semana passada e com o meu chefe; eu fiz a minha solicitação de férias, e ele eletronicamente recebeu uma mensagem falando: 'olha tem férias aqui para você aprovar, por gentileza aprove o pedido de férias do Edson'. Entrou no sistema e aprovou. Do ponto de vista de tempo, nós ganhamos, pois tínhamos muita burocracia."

A democratização das informações foi um dos principais benefícios do projeto: 
"No passado o que se circulava era papel, não circulava informação. Hoje eu tenho um sistema em que eu marco férias, vejo currículo, promovo, transfiro, demito, e obtenho qualquer informação sem levantar da cadeira. Se alguma coisa não estiver aqui eu ligo e em pouco tempo tenho a resposta. Quando eles não a possuem, esta chega no máximo em um dia".

Além da maior rapidez e independência dos gestores nos processos de $\mathrm{RH}$, a informatização propiciou o aumento do acesso à informação relacionada à gestão de pessoas em todos os níveis da organização. Na medida em que o RH deixa de ser o intermediário entre chefes e subordinados por meio da informatização dos processos, o sistema organizacional passa a ter um nível maior de conhecimento sobre as práticas de gestão de pessoas. A democratização das informações e as novas ferramentas de gestão de pessoas tiveram diversas conseqüências no que diz respeito ao relacionamento entre chefes e subordinados: o menor poder vertical e a maior politização e responsabilidade nos relacionamentos. Um perfil mais qualificado e crítico de funcionários era estimulado através destas modificações. Os indivíduos passaram a negociar com sua chefia os interesses pessoais e organizacionais, na busca de melhores soluções para as questões de gestão de pessoas.

"Permitiu-se, com a instalação dos sistemas, que o funcionário tenha um nível muito maior de acesso à informação, desta forma o cara passa a te demandar mais. O questionamento muitas vezes vem do acesso à informação, por esse aspecto aumenta a responsabilidade. Ao permitir o acesso, ele vai ter um nível de questionamento mais elevado".

"A idéia é sistematizarmos e disponibilizarmos aquelas informações que eles [os gerentes] precisam para gerir. Estas informações são várias, vou citar alguns exemplos: como está o status de férias da turma dele, como vão os treinamentos da área dele. Eu consigo fazer um acompanhamento do nível de despesa médica do empregado, por exemplo, eu poderia ver se ele está doente, pois está gastando muito com medicamento. Eu preciso então conversar com ele para saber se algo está acontecendo. Informações da própria folha de pagamento, quanto custa para ele, versus o que ele tem planejado, enfim são informações gerenciais relacionadas a ele e sua equipe, para que facilite a tomada de decisões, para que se redirecionem os esforços dele, essa é a idéia".

A democratização das informações sobre a gestão de pessoas e as novas ferramentas tecnológicas também permitiram mudanças na atuação dos analistas de RH em toda a organização. Atualmente, as estruturas de RH nas unidades ocupam-se do atendimento de demandas específicas sobre a administração de pessoas; do suporte às áreas clientes no que diz respeito à gestão de pessoas; e da tradução das demandas organizacionais para o desenvolvimento de políticas e serviços, em interação constante com o RH corporativo no Rio de Janeiro. As novas responsabilidades dos analistas de $\mathrm{RH}$ nas unidades foram descritas da seguinte maneira por executivos e analistas da área:

"Uma promoção exige um apoio amplo do RH, afinal não é só promover aquela pessoa, você tem que analisar as consequiências do ponto de vista legal e de outros aspectos políticos da companhia. O gerente não sabe o contexto de todos os cargos existentes na fábrica, inclusive no setor dele, os salários, ele fica em dúvida e nós damos esse suporte a ele. Não se trata de autorizar a promoção, mas deixá-lo ciente das vulnerabilidades e alternativas em relação a sua decisão. Trata-se de uma análise da situação, e não uma decisão, já que a decisão é dele".

'Temos que tomar providências rápidas para que a demanda [de gestão de pessoas] não seja geral. Eu vejo então o que está acontecendo na tela, o que está acontecendo numa unidade ou na empresa como um todo. Posso antecipar estas questões sendo mais pró-ativa. Identifiquei que tal assunto sempre me traz problema, logo antes desse problema acontecer, eu tenho que elaborar respostas para minimizar seus impactos".

No contexto do projeto CSRH, os conflitos mais relevantes potencializados pela implementação da TI coincidem com aqueles discutidos pela literatura especializada, e estão relacionados às grandes mudanças na organização do 
trabalho da área e nas responsabilidades pelas tarefas relacionadas à gestão de pessoas. A descentralização através da informatização, neste contexto, e a concessão de uma maior autonomia aos funcionários é especialmente problemática, por que implica na transferência de responsabilidades de várias atividades, da área de RH para as áreas clientes.

Desta maneira, a descentralização gerou grandes conflitos com as áreas clientes, acostumadas a terem menos responsabilidades, ou nenhuma, em diversos processos administrativos. Este conflito foi mais intenso com os gestores menos familiarizados com o trabalho informatizado, que, por terem dificuldades em se adaptar a esta modalidade de trabalho, viam a introdução do sistema como um grande aumento de suas tarefas diárias.

Os conflitos com a introdução da descentralização, entretanto, diminuíram na medida em que a organização foi compreendendo os grandes benefícios dos novos processos. A estratégia de implementação gradual acompanhada de um amplo processo de disseminação e treinamento foi essencial para a desmistificação da tecnologia. Os conflitos diminuíram na medida em que o tempo adicional gasto com determinadas rotinas e atividades passou a ser percebido como menor que o tempo economizado em outros aspectos dos novos processos.

\section{Mudanças na organização}

Um dos aspectos mais importantes da implementação deste projeto de informatização é o fato da organização ter progressivamente implantado modificações de caráter mais geral compatíveis com as exigências desta tecnologia. Exigindo um perfil de funcionário mais politizado, independente, capaz de processar e analisar informações, acessar a tecnologia e ser autônomo na gestão de processos, o projeto de auto-atendimento não teria sido implementado com sucesso se não tivesse sido parte de um processo de mudança organizacional mais complexo, no qual a Souza Cruz implementou um modelo de gestão próximo ao das organizações em aprendizagem, fazendo mudanças no perfil dos funcionários recrutado, na gestão de equipes, nos valores difundidos, nas formas de remuneração, nas políticas de desenvolvimento de pessoas e no desenho da estrutura organizacional.

De fato, os últimos quinze anos na organização foram marcados pela diminuição dos níveis hierárquicos da estrutura organizacional. De um modelo altamente verticalizado, a organização estrutura-se atualmente com três a quatro níveis hierárquicos a menos. O perfil educacional mudou e a média de escolaridade aumentou na empresa a partir de novas políticas de desenvolvimento humano e contratação de pessoas. A comunicação na organização melhorou, consequiência das mudanças na estrutura organizacional. Estas mudanças foram descritas da seguinte maneira por executivos da organização:

"Dez, quinze anos atrás, nós começamos a grande reestruturação em 1989-90, e aí sim os níveis começaram a cair. Você vê, temos a gerência e o analista, não tem mais ninguém nesse meio, logo a comunicação ficou muito mais fácil, hoje você interage muito mais. A proximidade com o superior imediato facilita a comunicação, o que nós já falamos nesses encontros você comunica e negocia."

"É um pessoal [que trabalha em funções de escritório] que está concluindo o terceiro grau, no mínimo, e tem em média de 25 a 30 anos, com cerca de até 5 anos de empresa em sua maioria, sendo que $60 \%$ é do sexo masculino e $40 \%$ feminino mais ou menos nessa fase. A grande maioria, cerca de $80 \%$, tem o superior concluído ou em conclusão."

As mudanças na organização descritas acima foram o pano de fundo para a introdução do projeto CSRH e da consolidação do novo modelo de consultoria interna de recursos humanos, viabilizado pela TI. Além destas mudanças, especificamente na área de RH a transformação do modelo de gestão de pessoas na última década na 
empresa implicou também em novas responsabilidades e novo perfil dos analistas, nova disposição espacial das equipes, melhoria na comunicação entre equipes e níveis hierárquicos, novas sistemáticas de desenvolvimento e remuneração etc.

\section{CONCLUSÃO: GESTÃo DO PARADOXO DISCURSO X PRÁTICA NA SOUZA CRUZ E OS DESAFIOS FUTUROS}

Pesquisas mostram que as organizações brasileiras encontram-se em uma fase de transição importante na implementação de suas políticas de gestão de pessoas e que uma das tendências é a implementação da tecnologia da informação para viabilizar modelos de gestão que favoreçam a aprendizagem (Fischer e Albuquerque, 2001; Lacombe e Tonelli, 2000; Mascarenhas, 2003). A pura implementação da tecnologia, entretanto, não garante a construção de competências técnicas e de um ambiente favorável à aprendizagem em circuito duplo.

A implementação de um sistema favorável à aprendizagem é algo mais complexo e requer a politização dos indivíduos, no sentido de estimular a autonomia de trabalho bem como a capacidade de questionamento e inovação. Trata-se da construção não só de um sistema técnico, mas de um sistema social que favoreça a aprendizagem em circuito duplo. Isso implica na gestão da mudança na direção de implantar-se um sistema técnico e social compatíveis com o modelo político de gestão de pessoas. A mudança de um sistema autoritário para um sistema mais politizado, favorável à aprendizagem, não é simples.

De fato, a mudança organizacional é um processo de criação coletiva através do qual os membros de uma dada coletividade inventam e fixam novas maneiras de jogar o jogo social da cooperação e do conflito, negociando interesses e instaurando uma nova estrutura e uma nova ordem social. Não se trata apenas de uma mudança técnica, mas da instauração de novos jogos políticos, novas formas de controle de recursos, hábitos e práticas sociais que favoreçam a implementação efetiva da nova tecnologia, ferramenta ou modelo de gestão. Trata-se da construção de um novo sistema organizacional.

A contradição fundamental é que o novo sistema só pode ser construído a partir do sistema anterior, com o qual, no entanto, deve romper ao menos parcialmente, para instaurar uma nova distribuição de recursos e poder. $\mathrm{O}$ sistema anterior fornece a maioria das competências disponíveis para a criação do novo. Deve-se, pois, coordenar a transição dos atores sociais para o novo sistema organizacional negociando soluções com os diversos grupos de indivíduos. Caso a organização compatibilize bem a mudança de sistemas técnicos e informáticos com esta transição, favorecerá a estratégia informatizante descrita por Zuboff.

No contexto estudado, a implementação do conceito de consultoria interna de recursos humanos implicava na construção de um novo sistema organizacional. Estimulou-se a qualificação e a politização dos indivíduos por meio de ações como novas políticas de recrutamento e seleção, mudanças da estrutura organizacional, das formas de comunicação e gestão de equipes e da política de desenvolvimento de pessoas. Na medida em que o novo sistema organizacional foi gradualmente construído por meio destas mudanças, criouse com a implementação da tecnologia um ambiente propício à aprendizagem de circuito duplo. Os funcionários de RH desenvolveram habilidades e competências mais voltadas para a proposição de novas idéias e para a inovação das atividades de gestão de pessoas da organização. A implementação do sistema permitiu então a liberação destes funcionários de tarefas operacionais e abriu para eles possibilidades de se concentrarem em tarefas menos mecânicas e mais 
analíticas, contribuindo na formulação da estratégia da organização, na definição de novas competências, no treinamento e seleção de novos talentos, na análise do perfil dos funcionários e elaboração de planos de incentivos e desenvolvimento de carreiras, etc.

No que diz respeito aos funcionários dos outros departamentos, à medida que o RH deixou de ser intermediário nas negociações dos interesses entre os gerentes e subordinados, os indivíduos se aproximaram e passaram a dialogar mais para a gestão conjunta não só dos aspectos técnicos do trabalho, mas também das questões mais pessoais ligadas à operacionalização dos sistemas de RH (férias, avaliação de desempenho, etc.). Ao diminuir a distância entre chefias e subordinados; ao promover a negociação entre os grupos e ao promover a reforma da área de RH, levando os funcionários do setor para tarefas mais estratégicas, a organização permitiu a implantação da TI dentro de uma estratégia informatizante, conforme descrito por Zuboff, procurando estimular a aprendizagem em circuito duplo e a inovação no sistema organizacional.

A transformação destes aspectos da organização pode ser explicada por meio da implementação de um modelo político de gestão de pessoas, distanciando-se do modelo instrumental de gestão de pessoas. Neste processo, foi necessário abandonar alguns princípios do modelo instrumental, como a visão estritamente utilitarista dos indivíduos, que deveriam adaptar-se a uma estrutura organizacional pensada unilateralmente como sendo um instrumento racional de produção econômica. $\mathrm{O}$ modelo político propõe que a organização que pretenda viabilizar a aprendizagem deve assumir a complexidade do comportamento social e incorporar a idéia de conflito e divergência, tendo em vista os diferentes interesses dos grupos organizacionais.

A Souza Cruz diminuiu a polarização entre as dimensões discurso e prática e efetuou passos importantes para a criação de um sistema propício à aprendizagem em circuito duplo. No entanto, como colocam Argyris e Schön, os bloqueios à aprendizagem são muitos e a distância entre a teoria professada e a prática organizacional é uma realidade comum nas organizações atuais. Pode-se dizer que a aprendizagem não acontece naturalmente na medida em que é criado um ambiente favorável a ela e são dadas ferramentas tecnológicas para facilitála. A gestão de pessoas, portanto, precisa ir além da criação de um contexto propício à aprendizagem e viabilizar novas formas de gestão e comportamentos que a operacionalizem efetivamente.

Neste sentido, outras variáveis ainda se mostram relevantes. A questão da descentralização da gestão de pessoas para os gerentes de linha, por exemplo, deve receber tenção especial. Os gerentes de linha assumem um novo e importante papel, no qual o seu estilo de liderança e envolvimento com a dinâmica social dos grupos passam a ser dois componentes importantes do novo modelo de gestão de pessoas. A atuação dos gerentes de linha deve refletir os pressupostos básicos do modelo de gestão de forma a facilitar a construção desta nova dinâmica. A questão da capacitação dos analistas de RH também é muito relevante. As novas funções do $\mathrm{RH}$ requerem a qualificação dos seus profissionais para a execução de atividades especializadas, nas quais o seu papel principal é trazer conhecimento. É necessário portanto que eles estejam à altura dessas novas responsabilidades. Por se concentrarem historicamente em atividades consideradas operacionais, podemos argumentar que estes profissionais ainda devem se preocupar com o preparo teórico que embasa a utilização das ferramentas práticas.

Vemos que a consolidação de uma organização em aprendizagem e a institucionalização da aprendizagem em circuito duplo é um processo contínuo sempre a ser perseguido; não se trata de uma ação gerencial com um fim determinado no tempo e no espaço, mas de uma jornada permanente. A Souza Cruz mostra ter desempenhado bem estes passos. Pesquisas futuras poderão verificar se a empresa realmente criou os fundamentos duradouros de uma Learning Organization ou não. 


\section{REFERÊNCIAS BIBLIOGRÁFICAS}

ARGYRIS, C. On Organizational Learning. Cambridge : Blackwell.1992

ARGYRIS, C. E.; SCHÖN, D. Organizational learning: a theory of action perspective. Reading, Mass. : Addison-Wesley, 1978.

BRABET, J. Repenser la gestion des ressources humaines. Paris: Economica, 1993.

CARVALHO, C.; LOPES, F. Convergência estrutural e processual entre teatros e museus no Rio Grande do Sul. Campinas, Anais do ENANPAD, 2001.

FISCHER, A., A Constituição do Modelo Competitivo de Gestão de Pessoas no Brasil - um estudo sobre as Empresas Consideradas Exemplares, Tese de Doutoramento, Faculdade de Economia, Administração e Contabilidade da Universidade de São Paulo, 1998.

FISCHER, A., Um Resgate Conceitual e Histórico dos Modelos de Gestão de Pessoas, In:Fleury,M., (org.), As Pessoas na Organização. São Paulo, Editora Gente, 2002.

FISCHER, A. e ALBUQUERQUE, L. Tendências que Orientam as Decisões dos Formadores de Opinião em Gestão de Pessoas no Brasil, Campinas: Anais do Enanpad, 2001.

KETS DE VRIES, M. F. R. Organizational paradoxes: clinical approaches to management. New York, Routledge, 1995.

LACOMBE, B e TONELLI, M., O discurso e a Prática: O que nos Dizem os Especialistas e o que nos mostram as Práticas das Empresas sobre os Modelos de Gestão de Recursos Humanos. Florianópolis, Anais do Enanpad, 2000.

LEÃO JR., F. P. Formação e estruturação de campos organizacionais: um modelo para análise do campo cultural. Campinas. Anais do ENANPAD, 2001.

LETART, J., A look at virtual HR: How far behind am I? HRMagazine, Alexandria, Jun 1998. Disponível em Proquest Direct ABI/Inform: http://proquest.umi.com/pqdweb Acessado em Março/2002.

LEWIS, M. W. Exploring paradox: toward a more comprehensive guide. The Academy of Management Review, v. 25, n. 4, p. 760-76, 2000.

MASCARENHAS, A. Tecnologia da informação e gestão de pessoas: valor estratégico da TI na transição da área de RH, Dissertação de Mestrado apresentada a EAESP/FGV, São Paulo, 2003.

MERTON, R. Structure Sociale et Anomie. In Psychologie Sociale vol. (eds. A. Levy), Paris, Dunod, 1968

SELEME, A. e ANDRADE, A. Campo de aprendizagem: otimizando a mudança organizacional. Foz do Iguaçu, Anais do ENANPAD, 1999. 
SOARES, R. e PIMENTA, S. O homem e a máquina: de operador a expectador. Florianópolis, Anais do ENANPAD, 2000.

SOUZA, Y. Conversação e aprendizagem organizacional: perspectivas para a investigação. Florianópolis, Anais do ENANPAD, 2000.

TEIXEIRA, F.; HASTENREITER, H. e SOUZA, C. Diferenças entre inovação tecnológica e desempenho: evidências de uma rede de aprendizado. Campinas, Anais do ENANPAD, 2001.

VASCONCELOS, I. e VASCONCELOS, F. Gestão de Recursos Humanos e Identidade Social: Um Estudo Crítico, Revista de Administração de Empresas, São Paulo, EAESP/FGV, vol. 42, n.1, pp.6478, jan/mar.2002.

VASCONCELOS, I., MOTTA, F., PINOCHET, L., Tecnologia, Paradoxos Organizacionais e Gestão de Pessoas, Revista de Administração de Empresas, São Paulo, EAESP/FGV, vol 43, n.2, abril/maio/junho 2003, pp.94-106.

VIEIRA, M.M. e MISOCZKY, M. C. Instituições e Poder: explorando a possibilidade de transferências conceituais. Curitiba, Anais do ENEO, 2000.

YIN, R. Estudo de caso: planejamento e métodos. Porto Alegre, Ed. Bookman, 2001.

ZUBOFF, S., In the age of the smart machine: the future of work and power. New York, Basic Books, 1988.

ZUBOFF, S., Automatizar/Informatizar: As duas faces da tecnologia inteligente. Revista de Administração de Empresas, São Paulo, v. 34, n.6, Nov./Dez. 1994.

\section{Artigo recebido em 25.06.2004. Aprovado em 01.03.2004.}

\section{Isabella Vasconcelos}

Professora do departamento de Administração da FGV-EAESP. Doutora em Administração de Empresas.

Interesses de pesquis a: administração de recursos humanos e teoria das organizações.

E-mail: ivasconcelos@yahoo.com

Endereço: Av. 9 de Julho, 2029, $9^{\text {a }}$ andar Bela Vista - São Paulo - SP, 01313-902.

\section{André Ofenhejm Mascarenhas}

Doutorando e Mestre em Administração pela FGV-EAESP.

Interesses de pesquisa: administração de recursos humanos, simbolismo nas organizações, teoria das organizações.

E-mail: andremascar@gvmail.br

Endereço: Al. Ribeirão Preto, 438, ap. 702 Bela Vista - São Paulo - SP, 01331-000. 


\section{Flávio Carvalho de Vasconcelos}

Professor do Departamento de Administração Geral e Recursos Humanos da FGV-EAESP. Doutor em Administração de Empresas pela HEC-Ecole des Hautes Etudes Commerciales, Paris.

Interesses de pesquisa: estratégia e organizações.

E-mail: fvasconcelos@fgvsp.br

Endereço: Av. 9 de Julho, 2029, $9^{\text {a }}$ andar Bela Vista - São Paulo - SP, 01313-902.

\footnotetext{
${ }^{i}$ Esta pesquisa foi realizada com o apoio do NPP/EAESP/FGV - Núcleo de Pesquisas e Publicações da EAESP/FGV, e do CIA - Centro de Informática Aplicada da EAESP/FGV.
} 